\title{
Visual acuity and visual skills in Malaysian children with learning disabilities
}

This article was published in the following Dove Press journal:

Clinical Ophthalmology

18 September 2012

Number of times this article has been viewed

\author{
Mohd-Nor Muzaliha' \\ Buang Nurhamiza' \\ Adil Hussein' \\ Abdul-Rani Norabibas' \\ Jaafar Mohd-Hisham-Basrun' \\ Abdullah Sarimah ${ }^{2}$ \\ Seo-Wei Leo ${ }^{3}$ \\ Ismail Shatriah' \\ 'Department of Ophthalmology, \\ ${ }^{2}$ Biostatistics and Research \\ Methodology Unit, School of Medical \\ Sciences, Universiti Sains Malaysia, \\ Kelantan, Malaysia; ${ }^{3}$ Paediatric \\ Ophthalmology and Strabismus Unit, \\ Department of Ophthalmology, \\ Tan Tock Seng Hospital, Singapore
}

Correspondence: Ismail Shatriah Department of Ophthalmology, School of Medical Sciences, Universiti Sains Malaysia,

16I50 Kubang Kerian, Kelantan, Malaysia

Tel +609767 6354

Fax +6097653370

Email shatriah@kck.usm.my
Background: There is limited data in the literature concerning the visual status and skills in children with learning disabilities, particularly within the Asian population. This study is aimed to determine visual acuity and visual skills in children with learning disabilities in primary schools within the suburban Kota Bharu district in Malaysia.

Methods: We examined 1010 children with learning disabilities aged between 8-12 years from 40 primary schools in the Kota Bharu district, Malaysia from January 2009 to March 2010. These children were identified based on their performance in a screening test known as the Early Intervention Class for Reading and Writing Screening Test conducted by the Ministry of Education, Malaysia. Complete ocular examinations and visual skills assessment included near point of convergence, amplitude of accommodation, accommodative facility, convergence break and recovery, divergence break and recovery, and developmental eye movement tests for all subjects.

Results: A total of $4.8 \%$ of students had visual acuity worse than $6 / 12$ (20/40), $14.0 \%$ had convergence insufficiency, $28.3 \%$ displayed poor accommodative amplitude, and $26.0 \%$ showed signs of accommodative infacility. A total of $12.1 \%$ of the students had poor convergence break, $45.7 \%$ displayed poor convergence recovery, $37.4 \%$ showed poor divergence break, and $66.3 \%$ were noted to have poor divergence recovery. The mean horizontal developmental eye movement was significantly prolonged.

Conclusion: Although their visual acuity was satisfactory, nearly $30 \%$ of the children displayed accommodation problems including convergence insufficiency, poor accommodation, and accommodative infacility. Convergence and divergence recovery are the most affected visual skills in children with learning disabilities in Malaysia.

Keywords: Learning disabilities, Malaysian children, visual acuity, visual skills

\section{Introduction}

It has been estimated that $80 \%$ of children with specific learning difficulties have a poor ability to read. ${ }^{1-4}$ These children should be assessed by the ophthalmologist because some of these children may have treatable visual problems that accompany or contribute to their primary reading or learning disabilities. ${ }^{5,6}$

Children with specific learning disabilities experience more difficulty in reading when they are also suffering from visual skills problems. ${ }^{7,8}$ Numerous published reports have described visual skills in children with learning disabilities. However, these studies are mainly confined to those living in Europe ${ }^{9-19}$ and the USA. ${ }^{20-22}$ Data from Asian countries are extremely limited. ${ }^{23,24} \mathrm{We}$ aim to determine the visual acuity and visual skills in Malaysian children with learning disabilities attending primary schools in suburban Kota Bharu, district of Kelantan, Malaysia. 


\section{Methods}

We conducted a cross-sectional study to examine students with learning disabilities, aged between 8-12 years old, from 40 primary schools in the suburban Kota Bharu District of Malaysia commencing January 2009 until March 2010. The study protocol was approved by the Research and Ethical Committee, School of Medical Sciences, Universiti Sains Malaysia. The study complied with the Declaration of Helsinki. Written approvals were obtained from the Department of State Education, Kelantan and Ministry of Education, Malaysia. Informed consent was also obtained from parents or guardians of each student.

Kelantan is one of the 13 states located in Malaysia, with a land area of approximately 149,222 sq km. Kota Bharu is the state capital of Kelantan and is located $500 \mathrm{~km}$ from the main city known as Kuala Lumpur. There are a total of 96 registered primary schools in the Kota Bharu District, with 51,930 students from standard 2-6, aged from 8-12 years.

Sample size was calculated using power and sample size software calculation based on $17.0 \%$ prevalence of poor readers who had poor visual acuity, with a $95 \%$ confidence interval. ${ }^{21} \mathrm{~A}$ minimum of 1000 primary school children with learning disabilities was required for this study. Multistage cluster sampling was performed, and all 96 registered primary schools were numbered. A total of 40 schools were randomly selected using a quantum of numbered cards. The schools were selected if the numbers appearing on the card matched with the numbering of the schools.

The second selection involved selection of students with learning disabilities from 40 selected primary schools. Lists of these students from each selected school were obtained 2 weeks prior to the examination day. A random selection was performed to select 25 students with learning disabilities from each school.

Early Intervention Class for Reading and Writing (known as Kelas Intervensi Awal Membaca dan Mengira (KIA2M) in Malay language) has been implemented since 2000 into the education system in Malaysia to identify children aged 7 years old who have difficulty in reading and writing. ${ }^{25}$ Those who fail the test (obtained less than 50\% marks) are allocated to special rehabilitation classes, while those who pass are placed in the standard classrooms at the age 8-12 years.

The informed consents were distributed to the parents by the schoolteachers. A period of 1 week was allocated for parents to clarify any issues. The telephone number of the primary investigator was provided in the informed consent.
The informed consent forms were returned to the schoolteachers 1 week before the actual examination day.

We randomly recruited 25 children with learning disabilities aged 8-12 years in each selected primary school. The exclusion criteria were students who refused eye examination, unable to perform proper examination after three attempts, absent during the examination day, and refused consent from the parents or guardian.

A team consisting of a consultant ophthalmologist, trainee ophthalmologists, and optometrists were involved in examining children's eyes. The clinical examination was performed in an identified room in all selected schools.

All students with learning disabilities were tested for their distance and near visual acuity, and visual skills parameters that included near points of convergence, accommodative amplitude, accommodative facility, convergence and divergence break and recovery at near, and saccadic tracking skills. Stereoacuity test, cover test, intraocular pressure measurement, and anterior and posterior segment examinations, including cyclorefraction, were performed in all subjects to rule out other apparent ocular abnormalities.

Distance visual acuity was assessed for each eye separately using the Snellen chart at $6 \mathrm{~m}$. The students were asked if they were wearing glasses or had glasses with them. Near visual acuity testing using the Malay language was performed at a distance of $33 \mathrm{~cm}$ and was recorded using the N-points system.

Assessment of near point of convergence, accommodative amplitude, accommodative facility, convergence and divergence break, and recovery were performed as described by Grisham et al. ${ }^{21}$ The visual skills assessments were performed with best-corrected visual acuity in all students.

Assessment of near point of convergence was started by asking the student if the identified target was seen as single when the examiner held it approximately $20 \mathrm{~cm}$ in front of the student's eyes. The examiner moved the target slowly (at about 1 to $2 \mathrm{~cm}$ per second) towards the student's face and the student was instructed to inform the examiner when the target appeared double. The test was performed on the student's midline, as he/she tracked the target with his/her eyes. The endpoint was measured and recorded when the student reported seeing two targets (preferable response), or when the examiner saw one eye deviate from the target. It was repeated 3 times, and an average measurement was recorded. Near point of convergence at $8 \mathrm{~cm}$ and closer was considered 'good', while $9 \mathrm{~cm}$ or more was classified as 'poor'. 
Accommodative amplitude was assessed using an accommodative ruler (Occlud-A-Measure; Bernell, Mishawaka, IN) with a 6-point target at the larger end of the tool held approximately $20 \mathrm{~cm}$ from the student's face. The student was asked if the target was in focus or blurry. Once the target was in focus, the target was moved approximately $2 \mathrm{~cm}$ per second towards the student's face until the target appeared double. This measurement was taken 3 times and recorded on the data collection sheet. Amplitude of accommodation at $11 \mathrm{D}$ and closer was considered 'good', while $12 \mathrm{D}$ or more was grouped as 'poor'.

Accommodative facility was measured using $\pm 2.00 \mathrm{D}$ flipper lenses with a target (6-point word) held at $40 \mathrm{~cm}$. The test was done monocularly and the fellow eye was occluded. The lens was flipped each time the student informed the examiner that the target was seen clearly. This step was repeated for $30 \mathrm{~s}$ in each eye. The number of cycles completed in one minute (cpm) for each eye was recorded. The procedure was repeated on the fellow eye. A value of $10 \mathrm{cpm}$ and more was classified as 'good', while $9 \mathrm{cpm}$ or less was considered 'poor'.

Convergence and divergence break and recovery at a near distance were measured with a horizontal prism bar with prism diopter (PD) values of 1, 2, 4, 6, 8, 10, 12, 14, $16,18,20,25,30,35,40$, and 45 diopters (D) with the target (Occlud-A-Measure; Bernell) held at a $40 \mathrm{~cm}$ distance. The student was asked if the target could be detected. Next, the student was asked whether the target appeared single or double. Once the single target appeared visible, the prism bar was moved in relation to the student's eye until double images were observed. This point was considered 'break'. Subsequently, the motion of the prism bar was reversed until the student reported a single image. This point was considered 'recovery'. This procedure was first performed for the base in position over the left eye, and then repeated base out over the right eye.

Convergence break at $19 \mathrm{PD}$ or more and convergence recovery at $8 \mathrm{PD}$ or greater were considered 'good'. Convergence break at $18 \mathrm{PD}$ or less, and convergence recovery at $7 \mathrm{PD}$ or less were classified as 'poor'. Divergence break from 10 to $20 \mathrm{PD}$ and divergence recovery from 7 to 13 PD were considered good.

A developmental eye movement (DEM) test was used to evaluate saccadic tracking skills. The DEM test consists of three subtests, which include a pretest, vertical subtest, and horizontal test. The vertical subtest depends on the individual's visual verbal automatic calling skills. The horizontal subtest consists of numbers in a nonsymmetric horizontal array. The DEM test was conducted according to the standard protocols from the examiner's test instructions. ${ }^{26}$

The acquired data were analyzed using the Statistical Package for Social Sciences for Windows version 18 software (SPSS, Inc, IBM, Armonk, NY, USA). The demographic characteristics were analyzed using descriptive statistics and reported as mean, standard deviation, and percentages. All the data were entered twice to avoid mistakes before analysis. The Pearson chi-square was used to determine significant differences in the distribution of visual skills with age and sex. A $P$ value of $<0.05$ was considered statistically significant.

\section{Results}

We recruited 1010 primary school students with learning disabilities in the suburban Kota Bharu District, Malaysia. The details of age and sex are summarized in Figure 1. $95.2 \%$ (961 students) had visual acuity 6/12 (20/40) or better. This included $64.2 \%$ male and $30.9 \%$ female students. 96.4\% (974 students) aged 8-12 years had near acuity N6 or better, while $3.6 \%$ (36 students) had near acuity N10 or worse. There was $64.5 \%$ male and $31.9 \%$ females diagnosed with near acuity $\mathrm{N} 6$ or better. These results are shown in Table 1.

We noted that $86.0 \%$ (869 students) had good near point of convergence, while $14.0 \%$ (141 students) had convergence insufficiency. Convergence insufficiency was observed in $9.0 \%$ of males and $5.0 \%$ of female students. There were no statistically significant differences between near point of convergence and different age groups $(P=0.229)$ or sex $(P=0.646)$ (Table 2).

We observed that $28.3 \%$ (286 students) had poor amplitude of accommodation, which consisted of $19.1 \%$ male and $9.2 \%$ female students. There was statistically significant difference between amplitude of accommodation and different age groups $(P=0.038)$. However, there was no statistically significant difference between amplitude of accommodation and sex $(P=0.599)$ (Table 2).

We found that $26.0 \%$ (263 students) were diagnosed with accommodative infacility. This was observed in $16.1 \%$ of males and $9.9 \%$ of female students. There was a statistically significant difference between accommodative facility and different age groups $(P<0.0001)$, while no statistically significant difference was observed between accommodative facility and $\operatorname{sex}(P=0.089)$ (Table 2$)$.

Table 3 describes distributions of convergence break and recovery according to age and sex. A total of $12.1 \%$ 


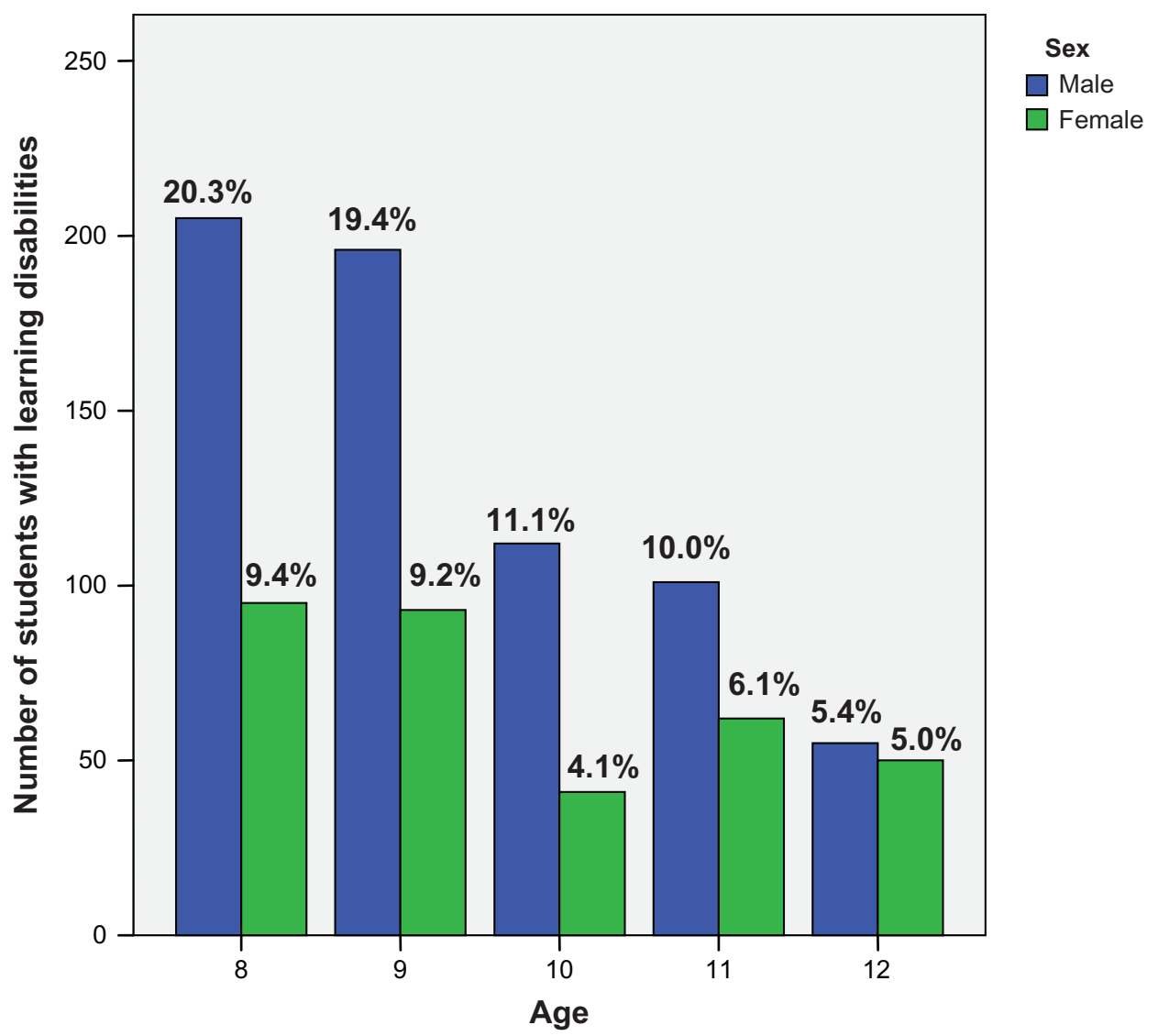

Figure I Distribution of poor readers according to age and sex.

(122 students) had poor convergence break and 45.7\% (461 students) had poor convergence recovery. Additionally, $7.7 \%$ of male and $4.4 \%$ of female students were noted to have poor convergence break. Poor convergence recovery was shown by $30.3 \%$ of male and $15.8 \%$ of female students (15.7\%). A statistically significant difference was observed between convergence break and different age groups $(P=0.024)$. However, there was no statistically significant difference between convergence recovery and different age

Table I Distribution of distance and near visual acuity

\begin{tabular}{|c|c|c|c|c|}
\hline & \multicolumn{2}{|c|}{ Distance visual acuity } & \multicolumn{2}{|c|}{ Near visual acuity } \\
\hline & $\begin{array}{l}\text { VA } 6 / 6-6 / 12 \\
n=961(\%)\end{array}$ & $\begin{array}{l}\text { VA } 6 / 18 \geq 6 / 60 \\
n=49(\%)\end{array}$ & $\begin{array}{l}\text { N5-N6 } \\
n=974(\%)\end{array}$ & $\begin{array}{l}\text { NIO-N20 } \\
n=36(\%)\end{array}$ \\
\hline \multicolumn{5}{|c|}{ Age (years) } \\
\hline 8 & $296(29.3)$ & $4(0.3)$ & $295(29.2)$ & $5(0.5)$ \\
\hline 9 & $277(27.4)$ & $12(1.2)$ & $277(27.4)$ & $12(1.2)$ \\
\hline 10 & $147(14.6)$ & $6(0.6)$ & $149(14.8)$ & $4(0.4)$ \\
\hline 11 & $149(14.8)$ & $14(1.4)$ & $156(15.4)$ & $7(0.7)$ \\
\hline 12 & $92(9.1)$ & $13(1.3)$ & $97(9.6)$ & $8(0.8)$ \\
\hline \multicolumn{5}{|l|}{ Sex } \\
\hline Male & $649(64.2)$ & $20(2.0)$ & $652(64.5)$ & $17(1.7)$ \\
\hline Female & $312(30.9)$ & $29(2.9)$ & $322(31.9)$ & $19(1.9)$ \\
\hline
\end{tabular}

Abbreviation: VA, visual acuity. groups $(P=0.024)$. No statistically significant difference was noted between convergence break or recovery and different age groups ( $P=0.817 ; P=0.948$, respectively).

There were $37.4 \%$ (376 students) with poor divergence break and $66.3 \%$ (670 students) with poor divergence recovery. $24.5 \%$ of male and $12.7 \%$ of female students had poor divergence break. Poor divergence recovery was shown by $44.6 \%$ of male and $21.7 \%$ of female students. A statistically significant difference was observed between divergence break and divergence recovery with different age groups ( $P=0.016 ; P=0.02)$. However, there was no statistically significant difference between divergence break, recovery, and sex $(P=0.736 ; P=0.323)$ (Table 3$)$.

The mean horizontal time and mean DEM ratio were noted as longer compared to normal DEM. There were statistically significant differences between mean vertical and horizontal times between different age groups. The $P$ value was $<0.001$ for both parameters (Table 4 ).

\section{Discussion}

Although visual problems are not the cause of learning disabilities, they have been known to interfere with the 
Table 2 Distribution of near point of convergence, amplitude of accommodation and accommodative facility

\begin{tabular}{|c|c|c|c|c|c|c|c|}
\hline & \multicolumn{3}{|c|}{ Near point of convergence } & \multicolumn{2}{|c|}{ Amplitude of accommodation } & \multicolumn{2}{|c|}{ Accommodative facility } \\
\hline & $\begin{array}{l}\text { Good } \\
n=869(\%)\end{array}$ & $\begin{array}{l}\text { Poor } \\
n=|4|(\%)\end{array}$ & $\begin{array}{l}\text { Mean } \\
\text { (SD) }\end{array}$ & $\begin{array}{l}\text { Good } \\
n=724(\%)\end{array}$ & $\begin{array}{l}\text { Poor } \\
n=286(\%)\end{array}$ & $\begin{array}{l}\text { Good } \\
n=747(\%)\end{array}$ & $\begin{array}{l}\text { Poor } \\
n=263(\%)\end{array}$ \\
\hline \multicolumn{8}{|l|}{ Age } \\
\hline 8 years old & $257(25.4)$ & $43(4.3)$ & $3.95(2.06)$ & $208(20.6)$ & $92(9.1)$ & $24 \mid(23.9)$ & $59(5.8)$ \\
\hline 9 years old & $255(25.2)$ & $34(3.4)$ & $4.04(1.92)$ & $195(19.3)$ & $94(9.3)$ & $213(2||)$. & $76(7.5)$ \\
\hline 10 years old & $128(12.7)$ & $25(2.5)$ & $4.24(2.23)$ & $123(12.2)$ & $30(3.0)$ & $119(11.8)$ & $34(3.4)$ \\
\hline II years old & $134(13.3)$ & $29(2.8)$ & $4.53(2.75)$ & $118(11.7)$ & $45(4.5)$ & $112(11.1)$ & $5 I(5.0)$ \\
\hline 12 years old & $95(9.4)$ & $10(1.0)$ & $4.24(3.33)$ & $80(7.9)$ & $25(2.4)$ & $62(6.1)$ & $43(4.3)$ \\
\hline$P$ value & \multicolumn{2}{|r|}{$0.229 *$} & $0.944 * *$ & \multicolumn{2}{|r|}{$0.038^{*}$} & \multicolumn{2}{|c|}{$<0.000 I^{*}$} \\
\hline \multicolumn{8}{|l|}{ Sex } \\
\hline Male & $578(57.2)$ & $91(9.0)$ & $4.15(2.22)$ & $476(47.1)$ & $193(19.1)$ & $506(50.1)$ & $163(16.1)$ \\
\hline Female & $291(28.8)$ & $50(5.0)$ & $4.13(2.56)$ & $248(24.6)$ & $93(9.2)$ & $24 \mid(23.9)$ & $100(9.9)$ \\
\hline$P$ value & \multicolumn{2}{|r|}{$0.646 *$} & $0.646^{* * *}$ & \multicolumn{2}{|r|}{$0.599 *$} & \multicolumn{2}{|c|}{$0.089 *$} \\
\hline
\end{tabular}

Notes: $*$ Chi-square test $(P<0.05$, considered significant); $* *$ one-way analysis of variance; $* * *$ independent $t$-test.

Abbreviation: SD, standard deviation.

process of learning. ${ }^{27,28}$ Visual skills include near point of convergence, accommodative amplitude, accommodative infacility, eye movement, control of binocular vergence eye movement, and convergent/divergent fusional reserve, which are essential in learning activities such as reading efficiency, reading comprehension, and copying from the board.

More than $90 \%$ of subjects with learning disabilities had good distance (6/12 or 20/40 and better) and near visual acuity (N6 and better). Our findings support existing data. ${ }^{21,24}$ Grisham et al reported that $82.9 \%$ of poor readers in four California high schools had better than $20 / 40$ visual acuity in each eye. ${ }^{21}$ Chen et al observed that $88 \%$ of children with low academic achievement in Kuala Lumpur, Malaysia had better than 6/12 (20/40) visual acuity. ${ }^{24}$ In contrast, other researchers reported poorer visual acuity in children with learning disabilities compared to normal children in studies conducted in Austria and Sweden. ${ }^{13,17}$
We observed that approximately one-third of our subjects demonstrated near vision-related problems. Poor convergence was observed in $14.0 \%$ of our subjects. Our finding was in agreement with that of Latvala et al. ${ }^{29}$ They reported that $25 \%$ of Finnish dyslexic children had convergence insufficiency.

We found no significant difference between near point of convergence and age or sex. However, we did not compare convergence skills in our subjects to normal children as was done in other studies. ${ }^{13,14,29}$ Dusek et al and Latvala et al reported that children with reading difficulties had poor convergence compared to normal children in their studied population. ${ }^{13,29}$ In contrast, Palomo-Alvarez et al noted that the near point of convergence was comparable in poor readers and normal children in Spain. ${ }^{14}$

Poor accommodative amplitude was observed in $28.3 \%$ of our subjects. Subjects aged 8-9 years old showed poorer amplitude of accommodation compared to older children. We

Table 3 Distribution of convergence and divergence break and recovery

\begin{tabular}{|c|c|c|c|c|c|c|c|c|}
\hline & \multicolumn{2}{|c|}{ Convergence break } & \multicolumn{2}{|c|}{ Convergence recovery } & \multicolumn{2}{|c|}{ Divergence break } & \multicolumn{2}{|c|}{ Divergence recovery } \\
\hline & $\begin{array}{l}\text { Good } \\
\mathrm{n}=\mathbf{8 8 8}(\%)\end{array}$ & $\begin{array}{l}\text { Poor } \\
n=122(\%)\end{array}$ & $\begin{array}{l}\text { Good } \\
\text { n= } 549(\%)\end{array}$ & $\begin{array}{l}\text { Poor } \\
n=46 I(\%)\end{array}$ & $\begin{array}{l}\text { Good } \\
n=634(\%)\end{array}$ & $\begin{array}{l}\text { Poor } \\
n=376(\%)\end{array}$ & $\begin{array}{l}\text { Good } \\
n=340(\%)\end{array}$ & $\begin{array}{l}\text { Poor } \\
n=670(\%)\end{array}$ \\
\hline \multicolumn{9}{|c|}{ Age (years) } \\
\hline 8 & $269(26.6)$ & 31 (3.I) & $166(16.4)$ & 134 (13.3) & I8I (I7.9) & 119 (II.8) & $94(9.3)$ & $206(20.5)$ \\
\hline 9 & $254(25.1)$ & $35(3.5)$ & |5 | (I5.0) & 138 (13.7) & $182(18.0)$ & $107(10.6)$ & $88(8.7)$ & $201(20.0)$ \\
\hline 10 & 130 (12.9) & $23(2.3)$ & $83(8.2)$ & $70(6.9)$ & I0I (I0.0) & $52(5.1)$ & $69(6.8)$ & $84(8.3)$ \\
\hline II & 137 (13.6) & $26(2.6)$ & $89(8.8)$ & $74(7.3)$ & $98(9.7)$ & $65(6.5)$ & $55(5.4)$ & $108(10.7)$ \\
\hline 12 & $98(9.7)$ & $7(0.6)$ & $60(5.9)$ & $45(4.5)$ & 72 (7.I) & $33(3.3)$ & $34(3.3)$ & 7I (7.0) \\
\hline$P$ value & \multicolumn{2}{|c|}{0.024} & \multicolumn{2}{|c|}{0.736} & \multicolumn{2}{|c|}{0.016} & \multicolumn{2}{|c|}{0.002} \\
\hline \multicolumn{9}{|l|}{ Sex } \\
\hline Male & $59 \mid(58.5)$ & $78(7.7)$ & $366(36.2)$ & $303(30.0)$ & $421(4 I .7)$ & $248(24.5)$ & $218(21.6)$ & 45 I (44.6) \\
\hline Female & $297(29.4)$ & $44(4.4)$ & $183(18.1)$ & I58 (I5.7) & $213(2||)$. & 128 (12.7) & $122(12.1)$ & $219(21.7)$ \\
\hline$P$ value & \multicolumn{2}{|c|}{0.817} & \multicolumn{2}{|c|}{0.948} & \multicolumn{2}{|c|}{0.736} & \multicolumn{2}{|c|}{0.323} \\
\hline
\end{tabular}

Note: ${ }^{*}$ Chi-square test $(P<0.05$, considered significant). 
Table 4 Distribution of vertical and horizontal time, and mean developmental eye movement

\begin{tabular}{clll}
\hline & $\begin{array}{l}\text { Mean vertical } \\
\text { time (SD) }\end{array}$ & $\begin{array}{l}\text { Mean horizontal } \\
\text { time (SD) }\end{array}$ & $\begin{array}{l}\text { Mean DEM } \\
\text { ratio (SD) }\end{array}$ \\
\hline Age (years) & & & \\
8 & $40.63(13.43)$ & $81.42(38.40)$ & $1.74(0.33)$ \\
9 & $38.18(11.63)$ & $79.04(35.33)$ & $1.79(0.29)$ \\
10 & $35.59(10.18)$ & $68.42(24.12)$ & $1.77(0.28)$ \\
II & $36.08(13.25)$ & $71.53(31.69)$ & $1.77(0.30)$ \\
I2 & $34.11(9.81)$ & $63.20(20.86)$ & $1.73(0.29)$ \\
Pvalue* & $<0.0001$ & $<0.0001$ & 0.318 \\
\hline
\end{tabular}

Note: *One way ANOVA ( $P<0.05$, considered significant).

Abbreviations: DEM, developmental eye movement; SD, standard deviation.

postulated that difficulty in understanding the test instructions in these children might have contributed to this observation. More importantly, this may also suggest that children less than 10 years old have lower amplitude of accommodation than the expected level for their age. It is also an alarming finding, as Sterner et al noted a similar observation in their studied population aged 6-10 years old. ${ }^{30}$

Our finding is parallel with observations by Grisham et al who reported that $24.7 \%$ of their subjects had poor amplitude of accommodation. ${ }^{21}$ However, both our study and Grisham et al examined children with learning difficulties only. We noted that numerous studies showed agreement that children with learning disabilities have significant poor accommodative amplitude than normal groups. ${ }^{13,15,17,29}$

Monocular accommodative infacility was diagnosed in $26 \%$ of subjects in our study. Subjects aged 9 or lower showed a higher percentage of monocular accommodative infacility compared with older subjects. We observed no significant difference in accommodative facility and sex. Our finding contradicted the observation by Chen et al, who evaluated the accommodation system in Malay primary school children in Malaysia. ${ }^{31}$ Chen et al reported no age difference in accommodation facility. We postulated that this difference was due to a larger sample size and usage of $\pm 2.00 \mathrm{D}$ flipper lenses in our study. In contrast to our study, Chen et al examined normal Malay children in Years 1 through 6 in selected primary schools in our country.

Grisham et al reported that $23.6 \%$ of children reading poorly (average age, 15.4 years) had accommodative infacility, which was consistent with our finding. ${ }^{21}$ However, we did not perform a parallel comparison to normal children.

Other authors reported that the mean measurement of accommodative facility was significantly slower in children with learning disabilities compared to normal children. ${ }^{13,15}$ The mean facility values were reported to be $12.0 \pm 3.28 \mathrm{cpm}$ in Austrian children with reading difficulties and $12.76 \pm 1.93 \mathrm{cpm}$ in the control group $(P<0.001) .{ }^{13}$ In addition, binocular accommodative facility values were significantly lower in the Spanish children with reading difficulties than in control children $(4.9 \mathrm{cpm} \pm 3.1$ and $6.3 \mathrm{cpm} \pm 2.9 ; P<0.05){ }^{15}$

Our findings confirmed that the divergence skill was the most affected in children with learning disabilities in Malaysia. Poor convergence break was noted in $12.2 \%$ of our subjects and $45.7 \%$ had poor convergence recovery, while $37.4 \%$ of students were diagnosed with poor divergence break and $66.3 \%$ had poor divergence recovery.

Our findings support an earlier report by Grisham et al. ${ }^{21}$ They observed that $38 \%$ of children with poor reading skills had poor convergence break and $9.5 \%$ of students had poor convergence recovery, while $82 \%$ of the students had poor divergence break and $60 \%$ had poor divergence recovery.

The mean horizontal DEM time was prolonged in our subjects. The vertical time and DEM ratio was within the normal limit as in the published norms. We observed significant prolonged horizontal and vertical times in younger age groups. A similar observation was also reported by other published studies. ${ }^{16,22}$ Our finding supports the existing evidences that children with learning disabilities may have poor saccadic tracking skills. ${ }^{11,16,22,32,33}$

Our study is the first of its kind and was conducted in native Malay speaking children on the eastern coast of Peninsular Malaysia. However, it would be more informative if a control group was examined, and thus an appropriate comparison could be performed.

In conclusion, our findings support the existing data on visual skills in children with learning disabilities. ${ }^{9-24,32,33}$ Although most of these children have good visual acuity for distance and nearness, nearly $30 \%$ had near vision-related issues, mainly poor convergence, accommodative infacility, and had prolonged horizontal reading time.

This suggests that a more global and comprehensive approach is warranted in the ophthalmic care of children with learning disabilities, particularly in our home country. Ophthalmologists and optometrists are expected to work closely with educators to identify and treat these students at an earlier stage.

\section{Acknowledgments}

The authors would like to acknowledge Universiti Sains Malaysia for financial support via Short Term Grant (Grant No 304/PPSP/6139035). Special thanks to Department of State Education, Kelantan and Ministry of Education, 
Malaysia for their support and useful contributions to this study.

\section{Disclosure}

The authors report no conflicts of interest in this work.

\section{References}

1. Shaywitz SE, Shaywitz BA. The science of reading and dyslexia. JAAPOS. 2003;7(3):158-166.

2. Shaywitz SE. Dyslexia. N Engl J Med. 1998;338(5):307-312.

3. Torgesen JK. Catch them before they fail: identification and assessment to prevent reading failure in young children. Am Educ. 1998; 22(1-2):32-39.

4. Lyon GR. Report on learning disabilities research. LD Online. 1997. Available from: http://www.ldonline.org/article/6339. Accessed June 20, 2012.

5. Olitsky SE, Nelson LB. Reading disorders in children. Pediatr Clin North Am. 2003;50(1):213-224.

6. American Academy of Ophthalmology, Pediatric Ophthalmology/ Strabismus Panel. Preferred Practice Pattern Guidelines: Pediatric Eye Evaluations. San Francisco, CA: American Academy of Ophthalmology; 2007. Available from: http://one.aao.org/CE/ PracticeGuidelines/PPP_Content.aspx. Accessed June 15, 2012.

7. Goldstand S, Koslowe KC, Parush S. Vision, visual-information processing, and academic performance among seventh-grade schoolchildren: a more significant relationship than we thought? $\mathrm{Am} \mathrm{J}$ Occupational Ther. 2005;59(4):377-389.

8. Helveston EM, Weber JC, Miller K, et al. Visual function and academic performance. Am J Ophthalmol. 1985;99(3):346-355.

9. Evans BJ, Drasdo N, Richards IL. Investigation of accommodative and binocular function in dyslexia. Ophthalmic Physiol Opt. 1994;14(1):5-19.

10. Pavlidis GT. Eye movements in dyslexia: their diagnostic significance. J Learn Disabil. 1985;18(1):42-45.

11. Eden GF, Stein JF, Wood HM, Wood FB. Differences in eye movements and reading problems in dyslexic and normal children. Vision Res. 1994;34(10):1345-1358.

12. Bedwell CH, Grant R, McKeown JR. Visual and ocular control anomalies in relation to reading difficulty. Br J Educ Psychol. 1980;50(1):61-70.

13. Dusek W, Pierscionek BK, McClelland JF. A survey of visual function in an Austrian population of school-age children with reading and writing difficulties. BMC Ophthalmol. 2010;10:16.

14. Palomo-Alvarez C, Puell MC. Binocular function in school children with reading difficulties. Graefes Arch Clin Exp Ophthalmol. 2010;248(6):885-892.

15. Palomo-Alvarez C, Puell MC. Accommodative function in school children with reading difficulties. Graefes Arch Clin Exp Ophthalmol. 2008;246(14):1769-1774.

16. Palomo-Alvarez C, Puell MC. Relationship between oculomotor scanning determined by the DEM test and a contextual reading test in schoolchildren with reading difficulties. Graefes Arch Clin Exp Ophthalmol. 2009;247(9):1243-1249.

Clinical Ophthalmology

\section{Publish your work in this journal}

Clinical Ophthalmology is an international, peer-reviewed journal covering all subspecialties within ophthalmology. Key topics include: Optometry; Visual science; Pharmacology and drug therapy in eye diseases; Basic Sciences; Primary and Secondary eye care; Patient Safety and Quality of Care Improvements. This journal is indexed on Submit your manuscript here: http://www.dovepress.com/clinical-ophthalmology-journal
17. Ygge J, Lennerstrand G, Axelsson I, et al. Visual functions in a Swedish population of dyslexic and normally reading children. Acta Ophthalmologica. 1993;71(1):1-9.

18. Jiménez R, Pérez MA, García JA, González MD. Statistical normal values of visual parameters that characterize binocular function in children. Ophthalmic Physiol Opt. 2004;24(6):528-542.

19. Prado C, Dubois M, Valdois S. The eye movements of dyslexic children during reading and visual search: impact of the visual attention span. Vision Res. 2007;47(19):2521-2530.

20. Rosner J, Rosner J. Comparison of visual characteristics in children with and without learning difficulties. Am J Optom Physiol. 1987;64(7):531-533.

21. Grisham D, Powers M, Riles P. Visual skill of poor readers in high school. Optometry. 2007;78(10):542-549.

22. Powers M, Grisham D, Riles P. Saccadic tracking skills of poor readers in high school. Optometry. 2008;79(5):228-234.

23. Roongpraiwan R, Ruangdaraganon N, Visudhiphan P, Santikul K. Prevalence and clinical characteristics of dyslexia in primary school students. J Med Assoc Thai. 2002;85(Supp 4):S1097-S1103.

24. Chen AH, Bleything W, Lim YY. Relating vision status to academic achievement among year-2 school children in Malaysia. Optometry. 2011;82(5):267-273.

25. Garis Panduan Pelaksanaan Program Pemulihan Khas 2008. Available from: http://www.searchinpdf.com/pdf/kia2m.htm. Accessed February 25, 2012.

26. Garzia RP, Richman JE, Nicholson SB, Gaines CS. A new visual-verbal saccade test: the developmental eye movement test (DEM). JAm Optom Assoc. 1990;61(2):124-135.

27. Handler SM, Fierson WM, Section on Ophthalmology; Council on Children with Disabilities; American Academy of Ophthalmology; American Association for Pediatric Ophthalmology and Strabismus; American Association of Certified Orthoptists. Learning disabilities, dyslexia, and vision. Pediatrics. 2011;127(3):e818-e856.

28. Garzia RP. The relationship between visual efficiency problems and learning. In: Scheiman MM, Rouse MW, editors. Optometric Management of Learning-Related Vision Problems. Philadelphia, PA: Mosby Elsevier; 2006:210.

29. Latvala ML, Korhonen TT, Penttinen M, Laippala P. Ophthalmic findings in dyslexic schoolchildren. Br J Ophthalmol. 1994;78(8):339-343.

30. Sterner B, Gellerstedt M, Sjöström A. The amplitude of accommodation in 6-10-year-old children - not as good as expected! Ophthalmic Physiol Opt. 2004;24(3):246-251.

31. Chen AH, Abidin AHZ. Vergence and accommodation system in Malay primary school children. Malaysian J Med Sci. 2002;9(1):9-15.

32. Jainta S, Kapoula Z. Dyslexic children are confronted with unstable binocular fixation while reading. PLoS One. 2011;6(4):e18694.

33. Bucci MP, Brémond-Gignac D, Kapoula Z. Poor binocular coordination of saccades in dyslexic children. Graefes Arch Clin Exp Ophthalmol. 2008;246(3):417-428.

PubMed Central and CAS, and is the official journal of The Society of Clinical Ophthalmology (SCO). The manuscript management system is completely online and includes a very quick and fair peer-review system, which is all easy to use. Visit http://www.dovepress.com/ testimonials.php to read real quotes from published authors. 